ISSN 1561-8358 (Print)

ISSN 2524-244X (Online)

\title{
МАШИНОСТРОЕНИЕ, МЕХАНИКА
}

MECHANICAL ENGINEERING AND MECHANICS

УДК 621.86-78:539.3

https://doi.org/10.29235/1561-8358-2020-65-1-62-71
Поступила в редакцию 30.01.2020

Received 30.01.2020

\section{В.Я. Прушак, А.П. Дворник}

ЗАО «Солигорский Институт проблем ресурсосбережения с Опытным производством», Солигорск, Республика Беларусь

\section{МЕТОДИКА РАСЧЕТА ДВУХБАРАБАННОЙ ШАХТНОЙ ПОДЪЕМНОЙ МАШИНЫ}

Аннотация. На базе $3 \mathrm{AO}$ «Солигорский Институт проблем ресурсосбережения с Опытным производством» выполнена разработка и налажено импортозамещающее серийное производство двухбарабанных шахтных подъемных машин большой грузоподъемности с увеличенным диаметром навивочных барабанов - до 7 м. Для реализации проекта проведено комплексное исследование всех научно-технических аспектов создания данной техники с учетом материально-технических возможностей предприятий отечественного горного машиностроения. Одним из важных результатов такого исследования стала разработка усовершенствованной методики расчета основных элементов подъемной машины. Методика позволяет рассчитать прочностные параметры наматывающих барабанов, вала, механизма расцепления, элементов привода (сопрягающей муфты), подшипников совместно с принадлежащими анкерными креплениями, приведенные к нормальным условиям эксплуатации и к условиям аварийного обрыва каната. Методика включает расчет напряженно-деформированного состояния элементов навивочных барабанов с помощью метода конечных элементов и позволяет использовать полученные численные данные при моделировании напряженно-деформированного состояния основных узлов подъемной машины для расчета коэффициентов запаса ее прочности в условиях нормальной эксплуатации и в аварийных. Разработанная методика была успешно опробована в конструкторско-технологическом центре $3 \mathrm{AO}$ «Солигорский Институт проблем ресурсосбережения с Опытным производством» при разработке двухбарабанных шахтных подъемных машин с навивочными барабанами большого диаметра для скиповых подъемных установок Петриковского горно-обогатительного комплекса, а также при модернизации существующих подъемных установок на действующих рудниках ОАО «Беларуськалий».

Ключевые слова: аварийная ситуация, барабан, масса, машиностроение, момент, нагружение, подъемная машина, сила, эксплуатация

Для цитирования: Прушак, В.Я. Методика расчета двухбарабанной шахтной подъемной машины / В. Я. Прушак, А. П. Дворник // Вес. Нац. акад. навук Беларусі. Сер. фіз.-тэхн. навук. - 2020. - Т. 65, № 1. - С. 62-71. https://doi.org/10.29235/1561-8358-2020-65-1-62-71

Viktor Ya. Prushak, Alexander P. Dvornik

\author{
JSC “Soligorsk Institute of Resources Saving Problems with Pilot Production”, Soligorsk, Republic of Belarus
}

\section{METHOD FOR CALCULATING A TWO-DRUM MINE WINDER}

Abstract. In the Republic of Belarus, on the base of JSC "Soligorsk Institute for Resources Saving Problems with Pilot Production", the development and launch of import-substituting mass production of large-capacity double-drum mine winders with an increased diameter of winding drums up to 7 meters were fulfilled. Earlier, in the post-Soviet space, machines with similar technical characteristics were not produced. Accordingly, for the implementation of the project, a comprehensive study of all the scientific and technical aspects of the creation of this equipment was required, taking into account the material and technical capabilities of the enterprises of domestic mining engineering. One of the important results of this study was the development of an improved methodology for calculating the basic elements of a winder. The technique allows calculating the strength parameters of the winding drums, shaft, disengagement mechanism, drive elements (mating clutch), bearings

(C) Прушак В. Я., Дворник А. П., 2020 
together with their anchor fasteners, reduced to normal operating conditions and to conditions of emergency wire breakage. The methodology includes the calculation of the stress-strain state of the elements of the winding drums using the finite element method and allows using the obtained numerical data to simulate the stress-strain state of the main components of the hoisting machine to calculate its safety factors in normal operation and in emergency conditions. The developed methodology was successfully tested in the design and technological center of JSC "Soligorsk Institute for Resources Saving Problems with Pilot Production" during the development of double-drum mine winders with large diameter winding drums for skip hoisting units of the Petrikov mining and processing complex, as well as during the modernization of existing hoisting units at working mines of JSC "Belaruskali".

Keywords: emergency situation, drum, mass, mechanical engineering, moment, load, hoisting machine, strength, exploitation

For citation: Prushak V. Ya., Dvornik A. P. Method for calculating a two-drum mine winder. Vestsi Natsyyanal'nai akademii navuk Belarusi. Seryya fizika-technichnych navuk = Proceedings of the National Academy of Sciences of Belarus. Physical-technical series, 2020, vol. 65, no. 1, pp. 62-71 (in Russian). https://doi.org/10.29235/1561-8358-2020-65-1-62-71

Введение. Стратегическим приоритетом Республики Беларусь является инновационное развитие горного машиностроения. Для обеспечения роста эффективности производства калийных удобрений на ОАО «Беларуськалий» вводятся новые мощности по добыче руды. Поддержание и расширение рудной базы предприятия решалось вовлечением в отработку новых участков и горизонтов Старобинского месторождения калийных солей. С целью увеличения объемов производства построены и введены в эксплуатацию Краснослободский и Березовский рудники, ведется освоение Петриковского месторождения калийных солей, а также выполнены наземные геофизические работы для возведения в дальнейшем седьмого рудника - Дарасинского.

Изначально ОАО «Беларуськалий» комплектовалось исключительно импортными шахтными подъемными установками украинского производства на двигателях постоянного тока $2 Ц 6 \times 2,8$ У, БЦК-8/5×2,7, ЦР5 $\times 3,2 / 0,85$. Двигатели постоянного тока, используемые на данном оборудовании, сложные, требуют частого обслуживания, что делает их эксплуатацию дорогостоящей. В настоящее время срок эксплуатации большинства таких установок на предприятии составляет от 33 до 59 лет.

Отечественным горным машиностроением до настоящего времени не производились шахтные подъемные установки ввиду отсутствия соответствующего металлообрабатывающего оборудования, опыта изготовления. Но с развитием научного потенциала и технологического оснащения ЗАО «Солигорский Институт проблем ресурсосбережения с Опытным производством» стало возможным изготавливать шахтные подъемные установки в Республике Беларусь.

Постановка задачи исследования. Совершенствованию подъемных установок и разработке теории рудничного подъема уделялось первостепенное внимание на протяжении всей истории развития добычи полезных ископаемых подземным способом [1-3]. Однако практика проектирования и эксплуатации подъемных установок показывает, что технические возможности выбранного оборудования часто остаются недоиспользованными, или в процессе эксплуатации возникают неисправности, влекущие увеличение объема ремонтных работ. Институтом накоплен опыт эксплуатации, ремонта подъемных машин, замены их барабанов и валов.

Вопросы эксплуатации, ревизии и наладки подъемных машин отражены в [3], определения контактных напряжений в зоне работы каната и гладкого барабана и анализа напряженнодеформированного состояния каната, навиваемого на барабан, методом конечных элементов освещены в [4]. В работах $[5,6]$ приведена теория расчета и конструирования цилиндрических барабанов шахтных подъемных машин конечно-элементным моделированием тонкостенных подкрепленных конструкций в машиностроении по методике Hot Spot Stress, установлена целесообразность применения при их проектировании по упрощенной обобщенно-параметрической модели. В результате использования предложенного подхода возможно получение структурно оптимальной конструкции барабана подъемной машины с возможностью снижения расчетных значений напряжений в зоне концентраций. В [7] определены динамические нагрузки и ресурс одноканатных подъемных машин. Содержащиеся в литературных источниках методики поверочных расчетов работы барабанов ШПМ носят оценочный характер. Но поверочные расчеты реальной подкрепленной конструкции барабана вызывают при конечно-элементном моделировании определенные затруднения из-за проблем с моделированием концентраторов напряжений. 
Если рассматривать барабан с точки зрения теории упругости, то для тонких чаще всего применяют гипотезу Кирхгофа-Лява, по которой любое прямое волокно, нормальное к срединной поверхности до деформации, остается прямым и нормальным к срединной поверхности и после деформации. Кроме того, считается, что нормальными напряжениями в направлении, перпендикулярном к срединной поверхности, можно пренебречь по сравнению с основными напряжениями. Решение задачи сводится к интегрированию системы дифференциальных уравнений в частных производных высокого порядка при краевых условиях, определяемых характером сопряжения с другими частями конструкции [8].

Важным этапом при проведении экспертизы подъемных машин для продления сроков их эксплуатации является оценка остаточного ресурса его элементов и устройства в целом. При оценке остаточного ресурса по усталостной кривой достоверность оценки зависит от точности определения эквивалентных напряжений элементов подъемной установки [9]. В действующих методиках оценки остаточного ресурса эквивалентное напряжение принято определять по максимальному напряжению (РД 03-422-01 «Методические указания по проведению экспертных обследований шахтных подъемных установок». М.: ГУП «НТЦ “Промышленная безопасность”», 2001). Тем не менее величины нагрузок в элементах подъемных установок изменяются в течение цикла подъема груза. В рабочем режиме эксплуатации установка осуществляет подъем и спуск груза с разным спектром нагружения.

Определение нагрузок, испытываемых элементами подъемной установки с учетом всех процессов, происходящих при ее работе, при оснащении подъемных машин устройствами для регистрации параметров, системами постоянного контроля параметров в режиме реального времени и в непрерывном мониторинге режимов работы шахтной подъемной установки с двигателями постоянного тока, изменении характеристик, ее элементов и в отслеживании изменения этих характеристик с течением времени и с учетом наработанных методов расчетов напряженно-деформированного состояния барабанов подъемных машин, дает возможность определять эквивалентные напряжения элементов установки на участке равномерного движения, использовать их в системах безопасности при эксплуатации действующих шахтных подъемных установок [10].

Поэтому актуальной остается задача совершенствования методов расчета и проектирования шахтных подъемных установок, использования приводов переменного тока, новых материалов для подъемных машин с целью обеспечения рациональных технических характеристик, экономии материальных ресурсов и электроэнергии.

Методика расчета шахтных подъемных машин в нормальных и аварийных режимах. Подъемные машины с двумя цилиндрическими навивочными барабанами (рис. 1) применяются для однослойной навивки каната на двухскиповых и двухклетевых подъемах, а также для однососудных подъемов с противовесом. Один навивочный барабан, называемый фиксированным, жестко закреплен на коренном валу. Второй навивочный барабан, называемый переставным,
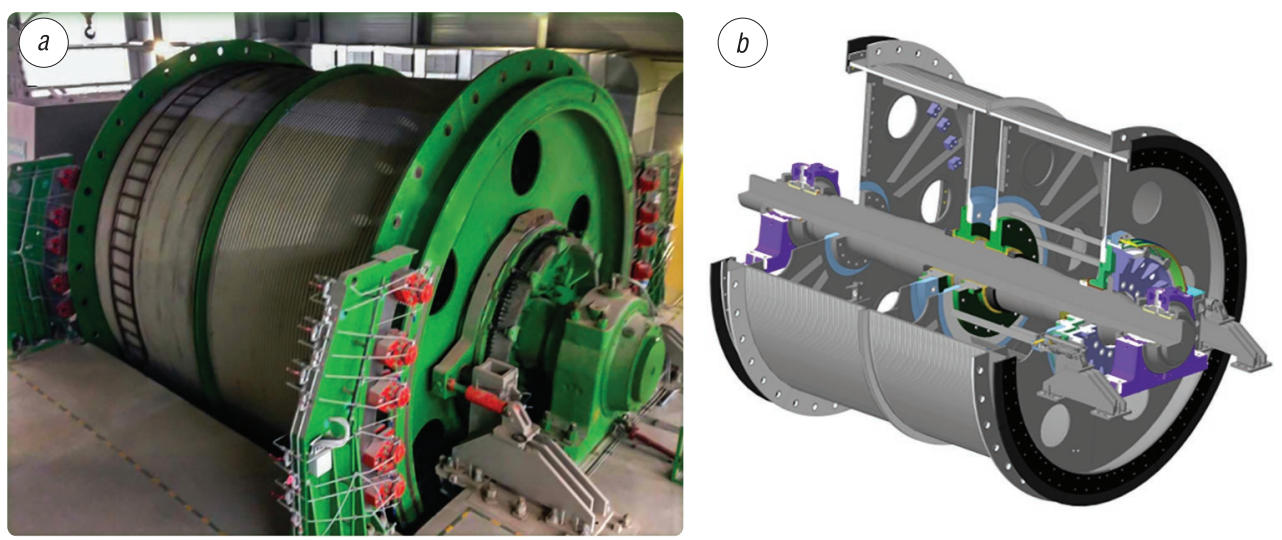

Рис. 1. Двухбарабанная шахтная подъемная машина $2 Ц-7 \times 3,2: a-$ установка подъемной машины на Петриковском ГОКе, $b$ - схема крепления барабанов на главном валу

Fig. 1. Double-drum winder 2 Ts $-7 \times 3.2: a$-installation of the winder at the Petrikovsky mining and processing plant, $b$ - the scheme of fixing the drums on the main shaft 
установлен на валу посредством скользящих подшипников и соединен с валом путем специального соединения - пружинно-гидравлического расцепного устройства зубчатого типа. Вал приводного электродвигателя, который соединен с главным (коренным) валом подъемной машины с помощью зубчатой муфты, установлен на двух скользящих подшипниках. Подъемная машина оснащена парой дисковых гидравлических тормозов. Тормозные приводы взаимодействуют с тормозными дисками навивочных барабанов машины.

Обечайка, выполненная в виде цилиндра, вальцованного из толстолистового металла, относится к осесимметричным цилиндрическим конструкциям, воспринимающим внешние равномерно-распределенные нагрузки по всей образующей обечайки или ее части от действия натяжения канатов. Лобовины частей барабана соединяются с главным валом двумя внешними и двумя внутренними ступицами вала при помощи болтов. Лобовины привариваются непрерывными сварными швами к участку обечайки.

Предлагаемая методика прочностного расчета двухбарабанной подъемной машины выполнена как для условий нормальной эксплуатации, так и для условий аварии, то есть для случая обрыва подъемного каната.

В качестве исходных в расчетах используются следующие параметры подъемной машины: глубина подъема, $H$, м; диаметр наматывающего барабана, $D$, мм; максимальная статическая сила, действующая в канате, $S, \mathrm{\kappa H}$; максимальный статический перевес $\Delta S$, кН; максимальный статический момент $M_{S}$, кН·м; диаметр несущего каната $d_{n}$, мм; удельная масса каната $q_{n}$, кг/м; минимальная сила обрыва несущего каната $P_{z \min }, \mathrm{\kappa H}$; максимальная сила обрыва несущего каната $P_{z \max }, \kappa \mathrm{H}$; максимальная скорость движения подъемного сосуда $v, \mathrm{м} / \mathrm{c}$; максимальное ускорение при движении сосуда $a, \mathrm{~m} / \mathrm{c}^{2}$; угол наклона каната при контакте с поверхностью барабана (в вертикальной плоскости) $\alpha$, град; высота от оси барабана подъемной машины до оси отклоняющего шкива $h$, м; расстояние от оси барабана подъемной машины до оси отклоняющего шкива $l$, м.

Методикой предусматривается определение максимальной статической силы в канате и статического перевеса. При этом для условия полного сосуда на уровне околоствольного двора определяются следующие параметры:

сила, действующая в канате на нагруженной стороне на уровне околоствольного двора:

$$
S_{1}=\frac{\left(m_{\mathrm{c}}+m_{\mathrm{\kappa c}}+m_{\text {гр }}+m_{\mathrm{\kappa H}}\right) \mathrm{g}}{1000}, \mathrm{\kappa H},
$$

где $m_{\mathrm{c}}$ - масса сосуда, кг; $m_{\text {кс }}$ масса подвесной конструкции сосуда, кг; $m_{\text {гр }}$ - масса груза, кг; $m_{\text {кн }}$ - масса каната, кг; $g$ - ускорение свободного падения Н/кг;

сила, действующая в канате на стороне без нагрузки на уровне околоствольного двора:

$$
S_{2}=\left(m_{\mathrm{c}}+m_{\text {кс }}\right) \mathrm{g} / 1000, \text { кН; }
$$

статический перевес для условия полного сосуда на уровне околоствольного двора:

$$
\Delta S_{1}=S_{1}-S_{2}, \kappa \mathrm{H}
$$

статический момент на валу при нахождении полного сосуда на уровне околоствольного двора:

$$
M_{S}=\Delta S \frac{D}{2}, \mathrm{\kappa H} \cdot \mathrm{M} .
$$

Для условия полного сосуда на уровне устья шахтного ствола рассчитываются следующие показатели:

сила, действующая в канате на нагруженной стороне на уровне устья шахтного ствола:

$$
S_{3}=\left(m_{\mathrm{c}}+m_{\mathrm{\kappa c}}+m_{\text {гр }}\right) \mathrm{g} / 1000, \mathrm{\kappa H} ;
$$

сила, действующая в канате на стороне без нагрузки на уровне устья шахтного ствола:

$$
S_{4}=\left(m_{\mathrm{c}}+m_{\text {кс }}+m_{\text {кН }}\right) \mathrm{g} / 1000, \kappa \mathrm{H} ;
$$

статический перевес при нахождении полного сосуда на уровне устья шахтного ствола:

$$
\Delta S_{2}=S_{3}-S_{4}, \kappa \mathrm{H} .
$$


Для условия перестановки барабана определяются следующие параметры: сила, действующая в канате на уровне околоствольного двора на стороне без нагрузки:

$$
S_{p B}=\left(m_{\mathrm{c}}+m_{\mathrm{\kappa c}}+m_{\mathrm{\kappa н}}\right) \mathrm{g} / 1000, \text { кН; }
$$

статический момент на валу при перестановке барабана:

$$
M_{s p B}=S_{p B} \frac{D}{2}, \kappa \mathrm{H} \cdot \mathrm{м} .
$$

Определение предельной силы, приводящей к обрыву каната, осуществляется в соответствии с требованиями «Правил промышленной безопасности при разработке подземным способом соляных месторождений Республики Беларусь» (Постановление МЧС Республики Беларусь от 30 августа 2012 г. № 45, с изменениями от 10 апреля 2014 № 10), согласно которым минимальная сила, необходимая для обрыва каната, равна

$$
P_{z r \min }=n_{u} S, \kappa \mathrm{H},
$$

где $n_{u}$ - нормативный запас прочности по максимальной статической нагрузке.

Максимальная сила для обрыва каната определяется по формуле

$$
P_{z r \max }=\frac{P_{z r \min }}{\eta}, \mathrm{\kappa H},
$$

где $\eta$ - эмпирический коэффициент.

Исходными параметрами для расчета привода являлись:

статический момент на главном валу подъемной машины:

$$
M=\Delta S \frac{D}{2}, \kappa \mathrm{H} \cdot \mathrm{M}
$$

частота вращения барабана (вала):

$$
n_{B}=\frac{v}{\pi D}, \text { об/c. }
$$

При расчетах используются следующие параметры нагрузки:

моменты инерции вращающихся элементов машины (узла главного вала, $J_{B W}, \kappa^{\circ} \cdot \mathrm{M}^{2}$; барабана, $J_{B}$, кг $\cdot \mathrm{M}^{2}$; двигателя, $J_{S}$, кг $\cdot \mathrm{M}^{2}$; зубчатой муфты, $J_{s z}$, кг $\cdot \mathrm{M}^{2} ;$ канатного колеса, $J_{k l}$, кг $\left.\cdot \mathrm{M}^{2}\right)$; масса, приведенная к диаметру наматывания каната и вычисляемая по формуле

$$
m_{z}=\frac{4 J}{D^{2}}, \kappa г ;
$$

где $J$ - момент инерции одного из вращающихся элементов машины, кг $\cdot$ м $^{2}$.

Общая приведенная масса подъемной машины рассчитывается следующим образом:

$$
m_{z m c}=m_{z B W}+m_{z s}+m_{z s z}, \kappa г,
$$

где $m_{z B W}-$ приведенная масса узла главного вала совместно с футеровкой, кг; $m_{z s}-$ приведенная масса двигателя, кг; $m_{z s z}-$ приведенная масса зубчатой муфты, кг.

При расчете нагрузки на двигатель для условий нормальной эксплуатации принимаются во внимание следующие параметры:

статический момент нагрузки двигателя $M_{S}$;

максимальное перетяжеление (избыточная динамическая масса) при пуске машины:

$$
\Delta S_{d}=\Delta S\left(1+\frac{a}{g}\right), \kappa \mathrm{H} ;
$$

динамический момент нагрузки на двигатель:

$$
M_{d}=\Delta S_{d} \frac{D}{2}, \mathrm{\kappa H} \cdot \mathrm{м} .
$$


Нагрузка на двигатель для аварийных условий определяется следующими параметрами: временная задержка для обрыва каната (пустой сосуд на уровне устья ствола):

$$
b=\frac{P_{z r}-S_{1}}{\left(m_{z m c}+H q_{n}+m_{1}^{\prime}+2 m_{z k l}+2(h+l) q_{n}\right)}, \mathrm{м} / \mathrm{c}^{2},
$$

где $m_{1}^{\prime}$ - масса нагруженной стороны приведенная к канату на уровне околоствольного двора, кг; крутящий момент для обрыва каната:

$$
M_{s a 1}=\left(P_{z r}-\left(m_{z k l}+(h+l+H) q_{n}+m_{z B}\right) b\right) \frac{D}{2}, \mathrm{\kappa H} \cdot \mathrm{M},
$$

где $m_{z k l}$ - приведенная масса канатного колеса, кг; $m_{z B}-$ приведенная масса барабана совместно с футеровкой, кг;

крутящий момент вала для обрыва каната:

$$
M_{s a 2}=\left(S_{1}+\left(m_{1}+m_{z k l}+(h+l) q_{n}+m_{z B}\right) b\right) \frac{D}{2}, \mathrm{\kappa H} \cdot \mathrm{M} ;
$$

усилия, действующие на барабаны:

$$
\begin{aligned}
& S_{a 1}=\frac{2 M_{s a 1}}{D}, \mathrm{\kappa H} ; \\
& S_{a 2}=\frac{2 M_{s a 2}}{D}, \mathrm{\kappa H} ; \\
& x=\frac{S_{a 1}+S_{a 2}}{P_{z r}} .
\end{aligned}
$$

Прочностные расчеты для фиксированного и переставного барабанов выполняются с помощью метода конечных элементов на основании многослоевых расчетов.

Усилие нажима, вызванного воздействием каната на поверхность барабана, определяется по формуле

$$
p=\frac{2 S}{D s}, \kappa \Pi а,
$$

где $s$ - шаг укладки каната, м.

Сила, действующая вдоль оси барабана при нормальных условиях эксплуатации, равна

$$
S_{p r}=S_{r} \sin (\alpha), \kappa \mathrm{H},
$$

где $\alpha$ - максимальный угол наклона каната при контакте с поверхностью барабана; $S_{r}$ - максимальная статическая сила в канате, кН.

Сила, действующая вдоль оси барабана при аварийных условиях эксплуатации, рассчитывается по выражению

$$
S_{p a}=S_{z} \sin (\alpha), \kappa \mathrm{H},
$$

где $S_{z}$ - сила, необходимая для обрыва каната, кН.

Касательная сила при нормальных условиях эксплуатации:

$$
S_{s r}=S_{r}, \kappa \mathrm{H} .
$$

Касательная сила при аварийных условиях:

$$
S_{p a}=S_{z}, \kappa \mathrm{H},
$$

Число витков, на которые воздействует сила обрыва каната, определяется следующим обра30м:

Угол обхвата равен

$$
i=\frac{\ln \frac{S_{z}}{S_{r}}}{\mu 2 \pi} .
$$

$$
\beta=i \cdot 360^{\circ} \text {. }
$$


Разработанная методика была использована на $3 \mathrm{AO}$ «Солигорский Институт проблем ресурсосбережения с Опытным производством» при проектировании двухбарабанной шахтной подъемной машины $2 Ц-7 \times 3,2$, а также при модернизации подъемных машин, установленных ранее на рудниках ОАО «Беларуськалий». Результаты моделирования напряженно-деформированного состояния переставного барабана шахтной подъемной машины $2 Ц-7 \times 3,2$ в условиях нормальной эксплуатации и в аварийных условиях (обрыв каната) представлены на рис. 2. Результаты моделирования напряженно-деформированного состояния фиксированного барабана указанной шахтной подъемной машины показаны на рис. 3. В таблице приведены полученные численные значения напряжений и деформаций элементов барабанов, полученных для стали S355J2 (европейский стандарт EN 10025-2) со следующими прочностными параметрами: предел прочности $R_{m}=450$ МПа, предел текучести $R_{e}=295$ МПа, предел выносливости $Z_{g o}=230$ МПа.
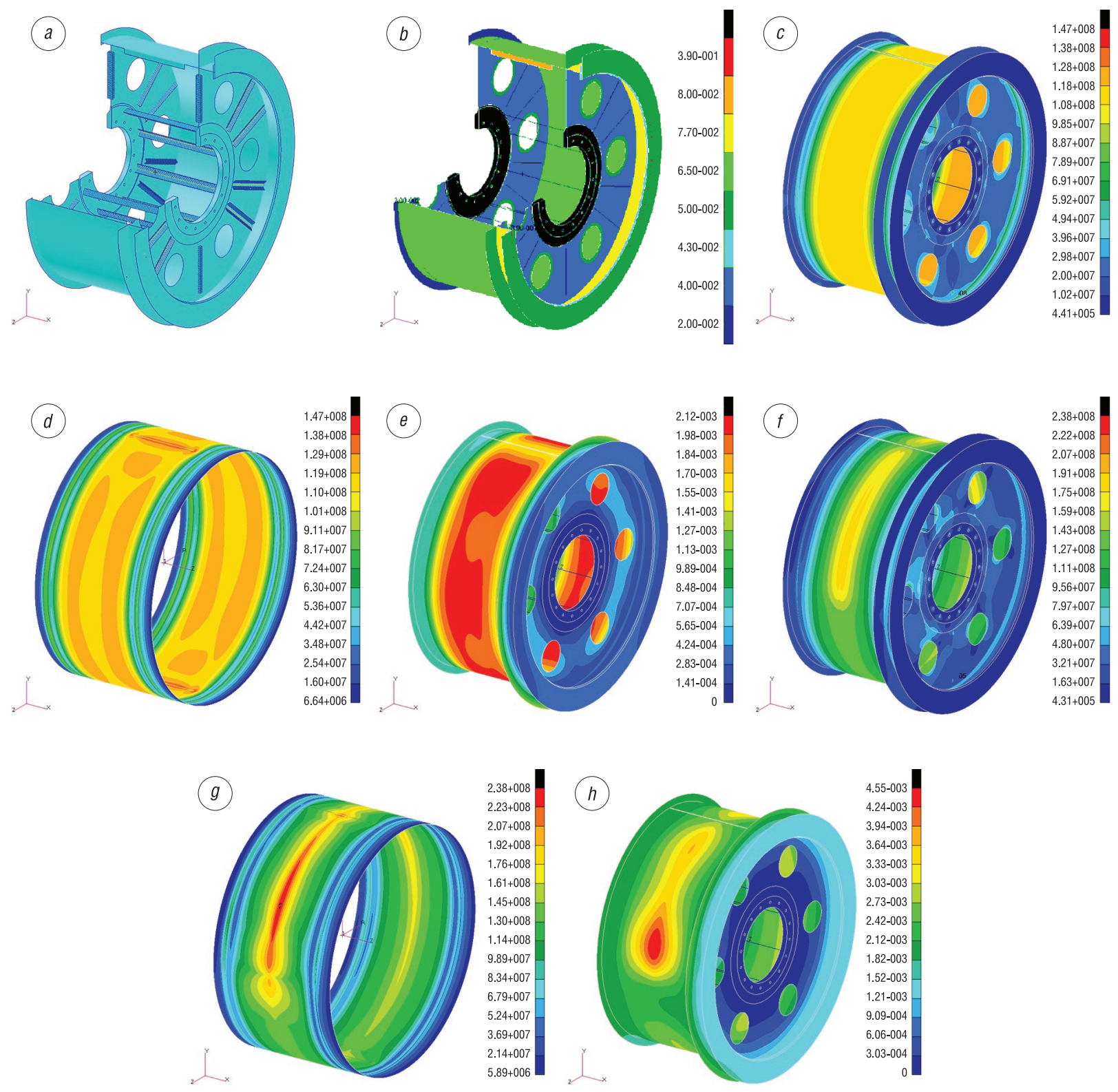

Рис. 2. Результаты моделирования напряжений и деформаций переставного барабана: $a$ - модель барабана, $b-$ карта толщины металла, $c$ - карта напряжений барабана, $d$ - карта напряжений обечайки, $e$ - карта деформаций, $f$ - карта напряжений барабана в аварийных условиях, $g$ - карта напряжений обечайки барабана в аварийных условиях, $h$ - карта деформаций барабана в аварийных условиях

Fig. 2. Simulation results of stresses and strains of the adjustable drum: $a$ - model of the drum, $b$ - map of thickness of the metal, $c$ - map of stresses of the drum, $d$-map of stresses in the shell, $e$ - map of deformations, $f$ - map of tension of the drum in an emergency, $g$ - map of stresses of the drum shell in an emergency, $h$ - map of deformations of the drum in an emergency 

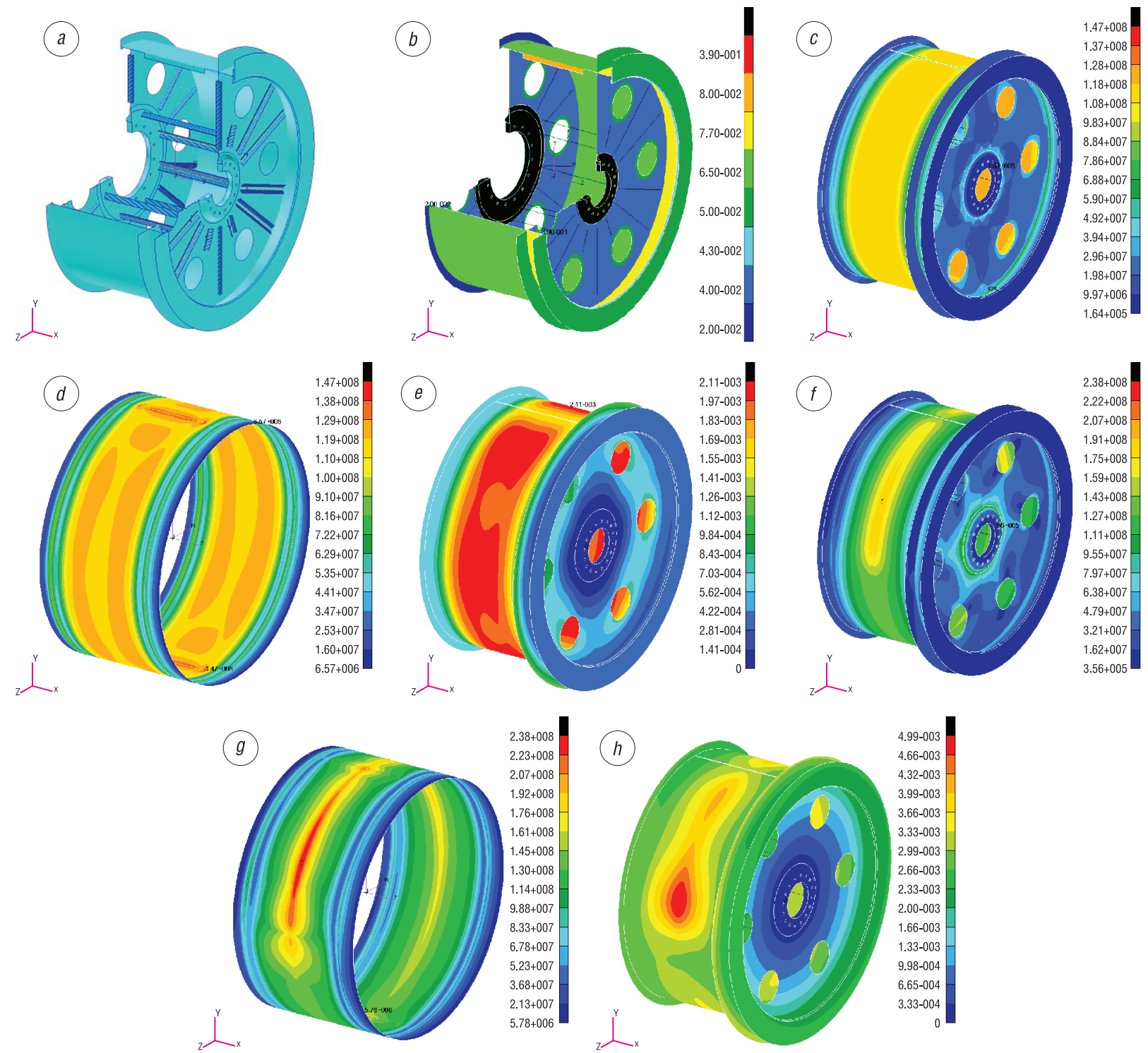

Рис. 3. Результаты моделирования напряжений и деформаций фиксированного барабана: $a$ - модель барабана, $b$ - карта толщины металла, $c$ - карта напряжений барабана, $d$ - карта напряжений обечайки, $e$ - карта деформаций барабана, $f$ - карта напряжений барабана в аварийных условиях, $g$ - карта напряжений обечайки барабана в аварийных условиях, $h$ - карта деформаций барабана в аварийных условиях

Fig. 3. Simulation results of stresses and strains of a fixed drum: $a$ - model of the drum, $b$ - map of thickness of the metal, $c$ - map of stresses of the drum, $d$ - map of stresses in the shell, $e$-map of deformations, $f$ - map of tension of the drum in an emergency, $g$ - map of stresses of the drum shell in an emergency, $h$ - map of deformations of the drum in an emergency

Результаты расчета напряженно-деформированного состояния навивочных барабанов Results of the calculation of the stress-strain state of the winding drums

\begin{tabular}{|l|l|c|c|c|c|}
\hline \multirow{2}{*}{ Тип барабана } & \multirow{2}{*}{$\begin{array}{c}\text { Составные } \\
\text { части барабана }\end{array}$} & \multicolumn{2}{|c|}{ Эксплуатационные условия } & \multicolumn{2}{|c|}{ Аварийные условия } \\
\cline { 3 - 6 } & $\begin{array}{c}\text { напряженности, } \\
\text { МПа }\end{array}$ & $\begin{array}{c}\text { деформации, } \\
\text { мм }\end{array}$ & $\begin{array}{c}\text { напряженности, } \\
\text { МПа }\end{array}$ & $\begin{array}{c}\text { деформации, } \\
\text { мм }\end{array}$ \\
\hline Переставной & Барабан в целом & 147 & 2,12 & 238 & 4,55 \\
& Обечайка & 147 & & 238 & \\
& Боковые диски & 101 & & 129 & \\
& Ступицы & 76,9 & & 95,5 & \\
\hline \multirow{5}{*}{ Фиксированный } & Барабан в целом & 147 & 2,11 & 238 & 4,99 \\
& Обечайка & 147 & & 238 & \\
& Боковые диски & 104 & & 136 & \\
& Ступицы & 90,7 & & 139 & \\
\hline
\end{tabular}


На основании полученных численных данных напряженно-деформированного состояния элементов навивочных барабанов рассчитываются коэффициенты запаса прочности основных узлов подъемной машины по пределу прочности и пределу текучести материала применительно к условиям нормальной эксплуатации по формулам:

$$
\begin{aligned}
& n_{m}=\frac{R_{m}}{\sigma}, \\
& n_{g o}=\frac{Z_{g o}}{\sigma},
\end{aligned}
$$

где $\sigma$ - максимальное расчетное напряжение, МПа.

Применительно к условиям аварийного обрыва каната коэффициенты запаса прочности основных узлов подъемной машины по пределу текучести определяют следующим образом:

$$
n_{e}=\frac{R_{e}}{\sigma}
$$

Заключение. В рамках проведенного исследования разработана оригинальная методика расчета двухбарабанных шахтных подъемных машин, оборудованных навивочными барабанами большого диаметра. Методика включает расчет напряженно-деформированного состояния элементов этих барабанов при нормальных условиях эксплуатации и в условиях аварийного обрыва каната с помощью метода конечных элементов и позволяет использовать полученные численные данные при моделировании напряженно-деформированного состояния основных узлов подъемной машины для расчета коэффициентов запаса ее прочности в условиях нормальной эксплуатации и аварийных. Данная методика была успешно опробована в конструкторско-технологическом центре ЗАО «Солигорский Институт проблем ресурсосбережения с Опытным производством» при разработке двухбарабанных шахтных подъемных машин с навивочными барабанами большого диаметра (7 м) для Петриковского горно-обогатительного комплекса, а также при модернизации существующих подъемных установок на действующих рудниках $\mathrm{OAO}$ «Беларуськалий».

Полученные результаты свидетельствуют о необходимости проведения дальнейших исследований при использовании современного полупроводникового электропривода, микропроцессорной системы управления, защиты, диагностики и контроля с развитым интерфейсом «человек-машина» на скиповых подъемных установках, а также обоснования динамических режимов движения сосудов в стволе в масштабе реального времени, проведения исследований сил сопротивления движению подъемных сосудов для обеспечения эффективности и безопасности подъемных машин.

\section{Список использованных источников}

1. Завозин, Л. Ф. Шахтные подъемные установки / Л. Ф. Завозин. - М.: Недра, 1975. - 367 с.

2. Белый, В.Д. Шахтные многоканатные подъемные машины / В.Д. Белый, И.С. Найденко. - М.: Недра, 1964. $-447 \mathrm{c}$.

3. Руководство по ревизии, наладке и испытанию шахтных подъемных установок / под общ. ред. В. А. Корсуна, Г. Д. Трифанова. - 4-е изд., перераб. и доп. - Пермь: Изд-во Перм. нац. исслед. политехн. ун-та, 2014. - 616 с.

4. Фидровская, Н.Н. Анализ напряженно-деформированного состояния каната, навиваемого на барабан, методом конечных элементов / Н.Н. Фидровская, А.А. Ломакин, А. С. Писарцов // Машинобудування: зб. наук. праць. Харків, 2016. - № 17. - С. 52-58.

5. Заболотный, К.С. Разработка теории расчета и конструирования цилиндрических барабанов шахтных подъемных машин / К.С. Заболотный, А. Л. Жупиев, М. А. Рутковский; М-во образования и науки Украины, Нац. горн. ун-т. - Днепр: НГУ, 2016. - 166 с.

6. Заболотный, К.С. Конечно-элементное моделирование тонкостенных подкрепленных конструкций в машиностроении / К. С. Заболотный, Е. В. Панченко // Наук. пр. Донец. нац. техн. ун-ту. Сер.: Електротехніка і енергетика. - Донецк, 2017. - № 1 (18). - С. 87-94.

7. Стрелков, М.А. Определение динамических нагрузок и ресурса одноканатных шахтных подъемных установок: автореф. дис. ... канд. техн. наук: 05.05.06 / М. А. Стрелков; Перм. гос. техн. ун-т. - Екатеринбург, 2011. - 17 с.

8. Зверяев, Е.М. Конструктивная теория тонких упругих оболочек / Е.М. Зверяев // Препринты ИПМ им. М. В. Келдыша. - 2016. - №33. - 25 с.

9. Попов, Ю. Методика определения остаточной ресурсности элементов и узлов шахтных подъемных машин (ШПМ) / Ю. Попов, С. Тимухин // Горн. информ.-аналит. бюлл. Спец. вып.: Экономика и экономические науки; Горное дело; Организация и управление; Охрана окружающей среды; Экология человека. - 2014. - № 6.

10. Современные системы безопасности при эксплуатации действующих шахтных подъемных установок/ Г. Д. Трифанов [и др.] // Вестн. Перм. нац. исслед. политехн. ун-та. - 2011. - Вып. 1. - С. 173-188. 


\section{References}

1. Zavozin L. F. Mine Hoisting Units. Moscow, Nedra Publ., 1975. 367 p. (in Russian).

2. Belyi V. D., Naidenko I. S. Mine Multi-Rope Winders. Moscow, Nedra Publ., 1964. 447 p. (in Russian).

3. Korsun V. A., Trifanov G. D., eds. Guide to the Revision, Adjusting and Testing of Mine Hoisting Installations. Perm', Publishing House of the Perm National Research Polytechnic University, 2014. 616 p. (in Russian).

4. Fidrovskaya N. N., Lomakin A. A., Pisarcov A. S. Analysis of the stress-strain state of a rope wound on a drum by the finite element method. Mashinobuduvannya: zbirnik naukovikh prats' [Engineering: Collection of Scientific Papers]. Kharkov, 2016, no. 17, pp. 52-58 (in Russian).

5. Zabolotnyi K. S., Zhupiev A. L., Rutkovskii M. A. Development of the Theory of Calculation and Design of Cylindrical Drums of Mine Hoisting Machines. Dnepr, National Mining University, 2016. 166 p. (in Russian).

6. Zabolotny K. S., Panchenko E. V. Finite-element modeling of thin-walled reinforced structures in mechanical engineering. Naukovi pratsi Donets'kogo Natsional'nogo tekhnichnogo universitetu. Seriya: Elektrotekhnika i energetika [Scientific Works of Donetsk National Technical University. Series: Electrical Engineering and Power Engineering]. Donetsk, 2017, no. 1 (18), pp. 87-94 (in Russian).

7. Strelkov M. A. Determination of Dynamic Loads and the Resource of Single-Rope Mine Hoisting Installations. Ekaterinburg, Perm State Tech. University, 2011. 17 p. (in Russian).

8. Zvereyaev E. M. Constructive theory of thin elastic shells. Preprinty IPM im. M. V. Keldysha [Preprints of M. V. Keldysh Institute of Applied Mathematics], 2016, no. 33. 25 p. (in Russian).

9. Popov Y., Timukhin S. Methodology for determining the residual life of elements and components of mine hoisting machines. Gornyi informatsionno-analiticheskii byulleten' Spetsial'nyi vypusk: Ekonomika i ekonomicheskie nauki; Gornoe delo; Organizatsiya i upravlenie; Okhrana okruzhayushchei sredy; Ekologiya cheloveka [Mining Information and Analytical Bulletin. Special issue: Economics and economic sciences; Mining engineering; Organization and management; Environmental protection; Human ecology], 2014, no. 6 (in Russian).

10. Trifanov G. D., Knyazev A. A., Trifanov M. G., Strelkov M. A. Modern security systems for the operation of existing mine hoisting installations. Vestnik Permskogo natsional'nogo issledovatel'skogo politekhnicheskogo universiteta [Bulletin of the Perm National Research Polytechnic University], 2011, iss. 1, pp. 173-188 (in Russian).

\section{Информация об авторах}

Прушак Виктор Яковлевич - член-корреспондент Национальной академии наук Беларуси, академик Евразийской академии горных наук, доктор технических наук, профессор, директор, ЗАО «Солигорский Институт проблем ресурсосбережения с Опытным производством» (ул. Козлова, 69, 223710, Солигорск, Минская область, Республика Беларусь). E-mail: ipr@sipr.by

Дворник Александр Петрович - кандидат технических наук, начальник отдела научно-технической информации, ЗАО «Солигорский Институт проблем ресурсосбережения с Опытным производством» (ул. Козлова, 69, 223710, Солигорск, Минская область, Республика Беларусь). E-mail: onti@sipr.by

\section{Information about the authors}

Viktor Ya. Prushak - Corresponding Member of the National Academy of Sciences of Belarus, Academician of the Eurasian Academy of Mining Sciences, D. Sc. (Engineering), Director, JSC "Soligorsk Institute of Resources Saving Problems with Pilot Production" (69, Kozlov Str., 223710, Soligorsk, Minsk Region, Republic of Belarus).E-mail: ipr@sipr.by

Alexander P. Dvornik - Ph. D. (Engineering), Head of the Department of Scientific and Technical Information, JSC "Soligorsk Institute of Resources Saving Problems with Pilot Production” (69, Kozlov Str., 223710, Soligorsk, Minsk Region, Republic of Belarus). E-mail: onti@sipr.by 